\title{
Modern Development Prospects of Programs in Engineering Education inside National University that Use Information and Communication Technologies
}

\author{
https://doi.org/10.3991/ijep.v10i3.12619 \\ Vitaliy A Prudnikov \\ Moscow Aviation Institute (National Research University), Moscow, Russia. \\ Prudnikovs64@mail.ru
}

\begin{abstract}
Article is devoted to studying of opportunities opened distribution in many countries at application of computer information support in production cycles. The interrelation and dependence of integration of such systems in production and trade technologies depending on extent of their development, availability and openness is discuses. As its positive indicator the humanitarian organization of their use in modern productions acts. The novelty of the opened opportunities shows the problems connected with their application, for example, change of ways of implementation of solutions of tasks. The possibility of complex assimilation of information systems for their universal use in practical activities occur today. Development of standards according to information and communication devices used in production and business is positive. The article is provide as the example created when training, forming contents in the systems of information supports parallel to the existing processes for effective monitoring of performance of work.

Development of these directions is very important for standardization of national programs in programs of bachelors and masters, with evidence follows from the Bologna declaration by the all-European education which the Russian Federation joined since 2003 [1]. The problem of educational standardization programs inside countries, E-learning and objectivity are to receive estimates of results and are still relevant and discuses.
\end{abstract}

Keywords-Parallelism, complexity, through technologies, inverse approaches, technological effectiveness, quality, efficiency, information support systems.

\section{Introduction}

Continuous transformations are interconnect with introduction of the automated systems to daily practice. Practically each modern technological innovation directly influences to social and labor sphere of public afire of the person. An integrated approach causes use of various hardware-software decisions, but demands training practical skills and also knowledge of engineering disciplines. At the same time development of productions happens in parallel and independent development of several directions of works, such as improvement of technologies, designing methods, normalization of tests 
programs and rationalization of the logistic tasks connected with deliveries and product sales at once. Use of information technologies has cross-disciplinary nature of application and use of knowledge and practical results. An important condition is ensuring educational process to appropriate levels of useful scientific knowledge providing complexity of the executed tasks. Many countries introduce various information and communication technologies in own practice. They are not producers of such equipment at the same time. It creates some difficulties for use of the called technologies in practice and carrying out preliminary training. In some countries, these problems can find solutions by means of high-quality professional translators, competent scientists, by participant technical commissions that are carrying out to help and support on creating training programs, E-learning, creation of textbooks.

Engineering specialties remain are demanded not only in mechanical engineering, but also in instrument making, construction, transport worldwide. Application of decisions on automation in these works has application, for example, in CALS technologies. They also have the international character of the introduction in different spheres of civil industries in the basis relying on the international integration [2]. Realization of the automated processes with information support bring as addition, accompanying technological lines and processes of management of machines and automatic machines, for example, in the form of the distributed information systems [3].

The role of the worker and operator of such devices comes down not only to function control and adoption of commands of process management, but also and to activity of ensuring diagnostics, the maintenance, to the choice of these or those decisions concerning performance of processes, to designing of products. It is important to reveal and define basic provisions leaning on which the person will be able easily and intuitively clear be able to carry out in the direction of his work for training in educational activity.

The detailed choice of architectural configurations, with the multiuser domains, for example, for the distributed information devices used in processes of the organization and management of production, trade and other specialized cycles is already apply to application of modern information support in the automated systems. Such systems are create in different configurations. They are create both about ready, and with the completed databases. Various scientific groups in Europe, America, China, Japan, in many countries carry out decades innovations on technical improvement of hardware-software decisions. Technical solutions taking by trade dress for information and communication devices extend the international corporations for application. The quality of compliance of the equipment already corresponds the international standards of the ISO group, being the group of the American standards allowed for application in other countries. Sometimes samples of the equipment demand recommendatory confirmation by the authoritative commissions possessing state and the national statuses for introduction in specific industries [4], [5], [6], [7] and [8]. Their application has uncontested nature of use. There is a detailed confirmation this reason in circles of experts of their technological capabilities that leads inside additional technical specifications. Education "as it is" carry out in creation of theoretical or training programs and provisions at the methodological level with prospects on future long-term demand is sensitive to such situations. 
Adoptions of such programs happen at the same time along with changes in courses of national education systems.

\section{$2 \quad$ Related Work}

There are technological, economic and social transformations permanently manifested in daily activities. They are clearly interlinked with introduction various automated systems into everyday practice. Every technological innovation directly effects on social and labor spheres of social activity for modern person. An integrated approach determines how it have been use various soft and hardware solutions for training practical skills inside of engineering disciplines. At the same time, the development of production occurs in parallel and independent development of several areas of work. At once, such as, for example, improving technologies, design techniques, testing systems, streamlining logistic tasks related to supplies and sales of products and so on. Unified educational could determine of information space for training future engineers. It is only first step towards innovation in production that should been implement through creation of coherent educational programs.

Machine-building solutions for production have already offered ready-made solutions for domains organization [9]. They know as information systems: CAD, CAM, CAPP, CAE and a number of others. Engineering tasks been allocated on multi-user automated systems for certain groups. They have been add as additional equipped elements as software tools for planning, supply, production management, implementation for coordination of issues. They are working together with external domains that provide work with customers and the market of suppliers.

Such systems are novelties in a number of countries. They already been actively applied and it show the innovative nature of their use in scientific, technical, commercial applications for trading companies. Their approbation reveals higher requirements for scientific training for production of machine-building profile. Breadth of tasks and a plurality added clarifications on hard and software solutions.

\section{Can Your Ensure Information System for Productions Cycle?}

\subsection{What is the systematic approach means?}

Manufacturing and machine-building enterprises were develop one principles of formalization of technological actions and algorithmic of repetitive operations on their classical developments. They are not change at all or change slowly during his life cycle of the industrial development. It was traditionally shows that union of turning and milling operations, transition them to processes fitting and assembly, while the normalization of production lines included. Many modern production facilities in Europe, America and Pacific-Asia region are examples of triumph of intellectual activity of its employees in modern engineering. Such companies as McDonnell Douglas, Pratt \& Whitney, NASA, Boston Dynamics, ESOC, Daimler AG, ADYDAS and many others are 
already habitually demonstrating to the world a high degree of implementation of automated solutions. International perspective of which is noticeable, predictable and realizing.

That can take into account that attributive conditions of the created products based on the complex representation in the system approach of such basic provisions as [9]:

1. Goals definition and created objects productions.

2. Alternatives analysis (search and analyzing possibilities technical solutions for solving problems).

3. Model creation and studding objects (machine designed, technological equipment, part of the process or tests).

4. Total costs calculation project and stages of its realizing (with an assessment of profitability and efficiency of their implementation).

5. Criteria determination for evaluation of results (for the project as a whole and its stages).

It was American engineer Hitch that been author provisions of the system approach. The system analysis has already taken into account a number of scientific sections: system control, decision theory, structural and functional analysis, which are themselves based on the foundation of scientific principles of consistency: internal integrity, order, organization and objective methods of the theory of knowledge.

\subsection{Verbal form of systematic design}

How can determine the design and technological solutions sufficient to achieve the goal of design, production or design works? Constructive and technological solutions is consider as kind of design justification for creation of an objects in which not only technical characteristics and properties of the created product is achieved, but also a specific technological method for its implementation is determined. The design and technological solutions are included improvement of the technology of object creation, and solutions related to their properties as objects of manufacturing.

System design covers and includes groups of engineering tasks. They appear in various stages and in the areas of work in the implementation of new and standard solutions. High complexity, responsibility and difficulty of the task, in theoretical assessments include multiple disciplines, and interdisciplinary consideration. Such approaches have already been tested and published $[10,11,13]$. In this encyclopedia, the authors have considered many design tasks implemented based on the already established methodology, based on the application of a systematic approach and analysis in the consideration of design tasks in practical production. Characteristics of product quality determine the general criteria of efficiency products. For example, assessment quality of the aircraft are presented through: maximum altitude or maximum achieved speed, for missile technology - characteristics of maximum weight and size characteristics of the payload or achieved parameters of the orbits, etc. There are obtain themselves as detailed solutions to the problems of suitability of the machine for the task. Criteria are consider as obviously and are not acceptable on levels of defining indicators 
in technological operations. General criteria could not be register on a production's level. Quality off production is especially characteristic for each case.

The generalized criteria of efficiency of the created products in various works is define not equally. They can be several for one product and they cannot be normalize among themselves. They are determine by particular criteria for the quality of products. As it known that multi criteria problem is not rarely solved specifically with definition of important "in some senses", indicators. Such indicators cannot only be identified by combined in the target functions, but also declared their best, again "in a sense", values. Quality indicators are useful properties of production and understood through complex indicators realized in the directions of works: statement of a task at a stage of the specification; scientific and technical justification of the project; used materials and semifinished products; opportunities of productions. These indicators fit into the evaluation criteria for the effectiveness of solutions: suitability, optimality and superiority of products. They can be geometric dimensions, weight, wear resistance, etc.

The parts of work are considers together in the study of existing production reserves and the experience of previous design developments. They allow for technological forecasting. It is technological forecasting that shows not only the achievable characteristics of the future product, but also ways to improve the specific technological method of achievement them.

Technological process are usually already generate in manufacturing operations. As it was already note in this article, for machine-building industries, it is processes traditionally formalized as turning, milling, fitting and assembly types of work. Moreover, if the first two first types are well amenable to processes of automation, in plumbing and assembly work there is a wide variety of solutions, where such technical systems are presents in various options, There are is not necessarily automated those for some case.

Additional principles are added solutions lies trough: complexity and parallelism of the processes of design and implementation of technological support, creating opportunities for end-to-end technologies at the stages of design and technological preparation of production, inversion of selection of technological solutions. Inversion is open technology is considered through providing functions of products required properties and manufacturability of products using existing production capacities at design stage.

The result of application on this or similar techniques are consider as practical construction of design and technological solutions. They provide specified performance indicators that implemented both for technological processes and for the products created.

Scientific directions: Methodical support of Computerized Automated Information and Communication Systems for production and operational applications.

Three are other directions on cheer. Employees of the department teach students for training courses, on advanced training courses and distance learning.

Ways to improve technological support process design of products at the present stage creation there.

"Technological support of the process design" that means to creation of products in the technological process of production and testing with the improvement of machine and corresponding to its manufacture (technological) ground equipment. It is carry out 
in parallel, with the minimum possible time lag in relation to the process of designing new products.

Products at its creation is the stages of life cycle, such as research, design, development, serial production and operation. It comes from the beginning of creation the ideas about the machine until when it will be used in practice. Modern technological systems cover all stages of the product life cycle. This important element of the technological process (PT) is currently manifested when creation of any new products.

Models of technological processes hag formed on the principles of formalization and algorithmic. Since the writing of Adam Smith of his famous work "The wealth of the nation" and for existence time are enterprise as slow to change. What is a cause that determine quality?

Quality assurance means determining compliance with the criteria for competitiveness.

What are the criteria that determine the competitiveness of products?

1. Customer requirements.

2. The level of scientific and technical merit of the project.

3. Used materials and accessories.

4. The possibilities of production.

\subsection{How can organize local information system?}

Implementation of system are approaching corresponds to use of information systems that accompany them and ensure. If we will ignore the idea that information support systems are determine by the breadth and variety of versions, their implementation involves multi-step verification of tasks and validation of intermediate solutions.

There are methods [12], [14] recommending the independent creation of information support systems for technological processes. As example there are SADT-methodology IDEF diagrams. For their rules of construction, information systems are creates by specialized databases capable of processing information about properties of object (entities) and their characteristics (attributes). At the same time, other systems have been developed and used (such as UG NX, ADEM, etc.) for which ready-made solutions are accompanied by already formed information support systems.

\section{Experiment for Higher Education}

\subsection{Procedure and instruments}

Procedures and examples showing the description of information systems as based on the basic schematic elements: star and snowflake (Fig 1 and 2). Schemes that was create on this basis allow collecting information about products in more detail. This detail are include the required refinements and characteristics, structuring and grouping information about the product. The main definitions are the concepts of "entity" and 
"attribute properties", in which the entity itself is the first "attribute property" of such system [9].

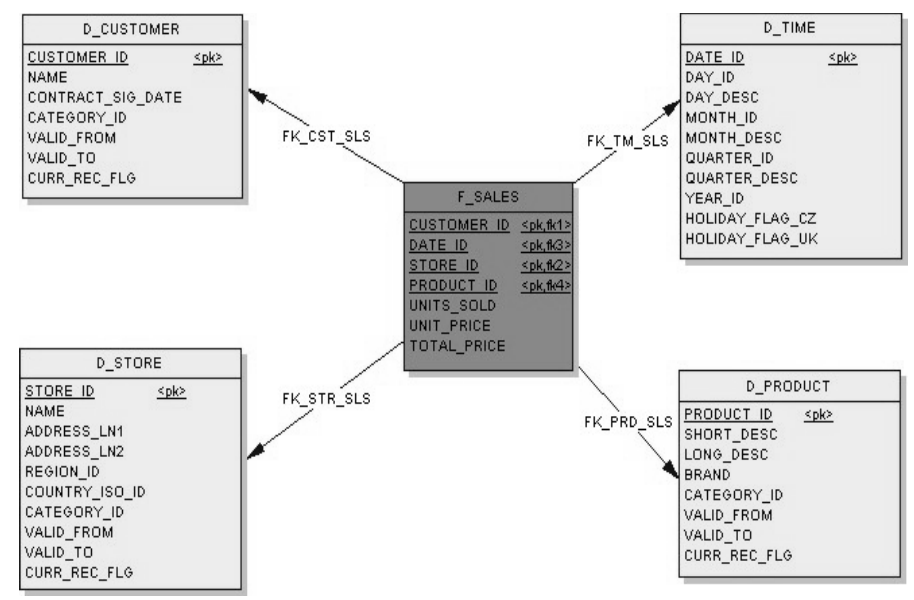

Fig. 1. Configuration basic schematic elements - star.

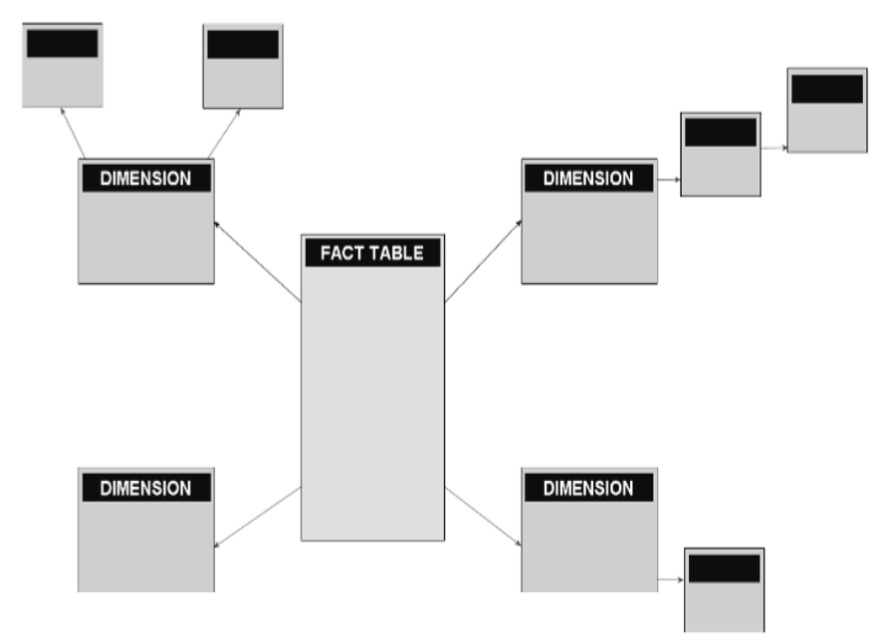

Fig. 2. Configuration basic schematic elements - snowflake.

There are databases formation schemes of specialized purpose used for creation of programs providing technological processes. As an example in this article will show the application of information system for trade in furniture by the individual order is resulted.

Together with software applications to carry out loading and processing of such system as database for a specialized information system. Such information systems and like this have already been tested and implemented in small and medium-sized businesses. They have a satisfactory implementation effect and do not have a level strictly 
recommended for use, but they used at request of entrepreneurs. At the same time, it is clear that the development of these systems to the level of medium-sized businesses and above shows the management of significant fixed assets. The figure below, as an example, shows a diagram of the order execution scheme of the existing business process of furniture manufacturing (second-level scheme), they display the stages of ordering for the manufacture of furniture (Fig. 3). It also shows the relationships, entities, and attributes that were define in Table 1.

Table 1. Schema Produktion (Second Level).

\begin{tabular}{|c|c|c|}
\hline Part A1 & & Checkout \\
\hline & Entrance: & Appeal of client. \\
\hline & Output: & Registration of the order form. \\
\hline & Management: & State standards, laws, regulations, information. \\
\hline Movement: & & Account manager. \\
\hline \multirow{4}{*}{ Part A2. } & & Design. \\
\hline & Entrance & Order form. \\
\hline & Output: & Ready project. \\
\hline & Managemen: & State standards, laws, regulations, information. \\
\hline Movement: & & Designers \\
\hline \multirow{4}{*}{ Part A3 } & & Manufacturing. \\
\hline & Entrance & Project, materials and semi-finished products. \\
\hline & Output: & Produced products. \\
\hline & Management: & State standards, laws, regulations, information. \\
\hline Movement: & & Furniture masters \\
\hline \multirow{4}{*}{ Part A4 } & & Delivery and installation to the consumer \\
\hline & Entrance & Finished products as part of the product. \\
\hline & Output: & Order confirmation after installation at the customer's address. \\
\hline & Management: & State standards, laws, regulations, information. \\
\hline Movement: & & Customer Service Manager \\
\hline
\end{tabular}

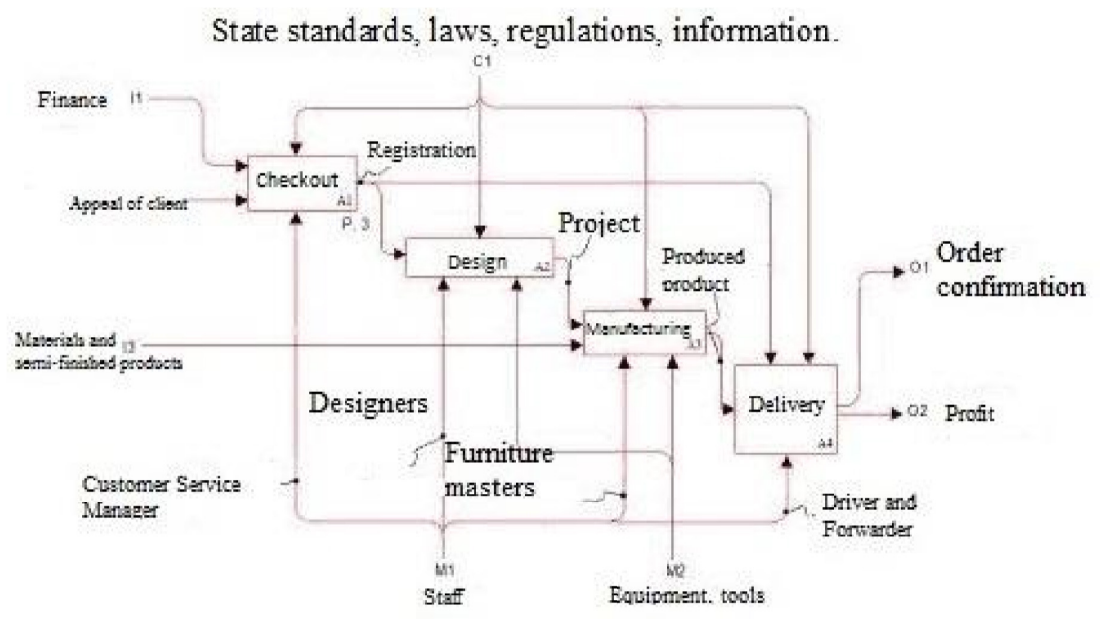

Fig. 3. IDEF0- diagram on second level production. 


\subsection{Mission}

Information systems is use as inextricably associated with the introduction of devices normalizing the work of automated processes in real time by reducing the importance of subjective errors, the implementation of services of choice of solutions from a number of available. They are create as typical elements that cause human actions, helping subjects to make decisions for actions in the processes of control and management of technological processes. The application purpose of such devices is quite promising and is obviously attractive for small and medium-sized businesses for research and production levels. At the same time, information support systems are not create as separate from processes, but complement more complex systems, together with calculators, communication devices, and technological lines [15].

ISO/IEC 12207 standards was announce and adopt on last century. The more general standard is ISO/IEC 15288 Systems Engineering. System life cycle processes followed in November 2002. It differs from ISO/IEC 12207 in the consideration of soft and hardware systems as a whole. ISO / IEC 15288 provided a similar scheme for considering a system life cycle as they set on processes. There was achieved describes each process as a results through various activities.

26 processes were allocated a total. They were grouped into 5 parts:

1. Agreement making processes

a) System acquisition.

b) Supply system.

2. Organization level processes.

a) Environmental management.

b) Investment management.

c) Process management.

d) Resource management.

e) Quality control.

3. Project Level Processes
a) Planning.
b) Evaluation.
c) Monitoring.
d) Management of risks.
e) Configuration management.
f) Information management.
g) Making decisions.

\section{Technical processes}
a) Determination of requirements.
b) Requirements analysis.
c) Architecture design. 
d) Implementation.

e) Integration.

f) Verification.

g) Validation.

h) Transfer to use;

i) Exploitation;

j) Support;

k) Decommissioning.

\section{Special processes:}

a) Adapting the processes described by the standard to the needs of a specific project.

In addition to the processes listed above, were fund 123 different type production were identify for 208 activities aimed at achieving technological results.

In additions to the ISO/IEC 12207 standard, additional definitions were introduce: the purpose of the process its results (outputs).

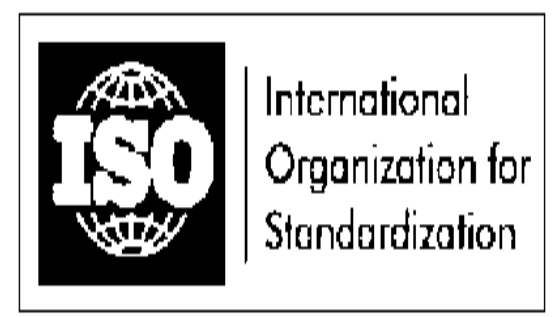

Fig. 4. ISO - International Organization for Standardization.

A reference process model has been defined that meets the requirements of ISO/IEC 15504-2. (Information Technology EVALUATION PROCESS Part 2 Conducting an assessment). The international standard ISO/IEC 12207: 2008 was introduce revised and revised supplements to the ISO/IEC 12207 standard (the emblem is show on Fig. 4). It is the first step in harmonizing specifications, with the goal of creating a fully integrated set on life cycle systems and software guidelines for their use.

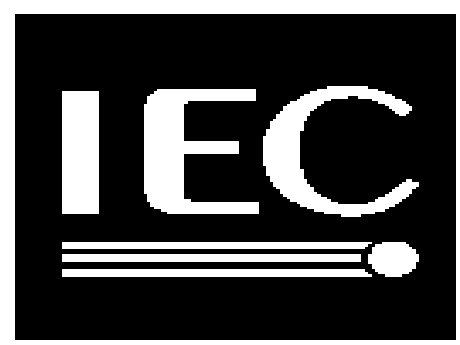

Fig. 5. IEC- International Electro Technical Commission. 
Established in 1946 by twenty-five national standardization organizations. The USSR entered their ranks as one of the founders of the organization and a permanent member of the governing bodies. The ISO field of activity concerns standardization in all areas, with the exception of electrical engineering and electronics, which are within the competence of the International Electro Technical Commission (IEC, IEC - emblem is show on Fig. 5). Some types of work are perform by joint efforts of these organizations. In addition to ISO standardization, it also deals with certification issues.

In 2005, Russian Federation also joined to ISO Council. There are 163 countries currently participating in ISO, with the headquarters of the organization in Geneva, Switzerland. Russia is represents in it by the Federal Agency for Technical Regulation and Metrology as an ISO member committee. There are more than 80 member committees in the ISO. In addition to member committees, ISO membership may have the status of corresponding members, which are the standardization organizations of developing countries. The category of member subscriber introduced additionally for developing countries. Member committees have the right to participate in the work of any ISO technical committee, vote on draft standards. They were elected to the ISO Council and be represented at meetings of the General Assembly. Corresponding members (there are 25 of them) do not actively work in ISO, but are entitled to receive information about being development standards. Subscribing members must pay preferential fees and have the opportunity to be aware of international standardization matters. IEC is an international non-profit organization for standardization in the field of electrical, electronic and related technologies. Some of the IEC standards were develops in collaboration with the International Organization for Standardization (ISO). The IEC made up of representatives of national standards services. It founded in 1906 and currently has more than 76 countries. Since 1948, their headquarters has been located in Geneva, Switzerland.

Methods and models of information systems design show the need to create a system of conceptual design techniques. They provides possibility of effective information exchange between all professionals who are participants in process of using such systems. The set of methods developed in the USA by the ICAM (Integrated Computer-Aided Manufacturing). Industry computerization program was calls IDEF (an acronym for Icam Definition or Integrated Definition). It includes the construction of a group of special-purpose diagrams.

The main diagrams are the methodology for the functional modeling of business processes IDEF0, the methodology for information modeling IDEF1X, the methodology for documenting the technological processes of the enterprise IDEF3, supplemented by the data flow analysis technology DFD. SADT methodology based the IDEF0 methodology and have initial step of building on integrated processes.

In the initial survey of enterprises, a functional model built AS IS. It allows you to record what business processes are carry out at the enterprise, what information objects are used when performing business processes and individual operations.

The functional model "AS IS" are starting point for analyzing the needs of the enterprise, identifying problems and "bottlenecks" of the project, in the proposed improvement of business processes. 
Creation and implementation of a corporate information system leads to a change in the conditions of operations, the structure of business processes and the enterprise as a whole.

Formation of a diagram related with "HOW WILL BE" or "HOW TO BE". The next step of designing an information system is functional model HOW WILL BE. Initial design stage determine how to changes processes registered by the information system in future. The use of a functional model "HOW WILL BE" not only reduce the time needed to implement an information system, but also reduce the risks associated with the immunity of personnel to information technology.

IDEF is an interconnected set of conceptual design techniques.

The principal requirement in the development of the considered family of methodologies was the possibility of an effective exchange of information between all the specialists involved in the development. The IDEF family is a technology for creating projects, covering all stages of the "life cycle" - from the initial analysis to the presentation form of the final project, through systematic process of creating diagrams and storing versions.

Unified Modeling Language UML / Graphic language for visual presentation, specification, design and documentation of systems in which software plays a major role.

The basis for the creation of UML were the methods of object-oriented analysis and design of complex systems:

1. The method of Booch (Booch'93), focused on software modeling of complex systems.

2. Rambo method (OMT-2), focused on the analysis of data processing processes in information systems.

3. Jacobson's method (OOSE), focused on the analysis of requirements for business applications.

The authors of these methods Gardie Buch (G. Booch), James Rumbaugh (D. Rambaugh) and Aivar Jacobson (I. Jacobson) united to create a unified modeling language for complex systems, which was call as UML. In 1996, the first version of UML 0.9 was create. After that, the companies Microsoft, IBM, Oracle and others organized a consortium of UML, whose activities were pay by the annual financial contributions of the firms of the members of the consortium.

Important role for creation of UML language was play by its support by the OMG Object Management Group, which unites about 300 leading computer companies.

In 1997, versions of UML 1.0 and 1.1 were create. The formal specification of the latest version of UML 2.0 was publishes in August 2005. UML 1.4.2 adopted as an international standard ISO / IEC 19501: 2005. To supporting process of building ontologies in IDEF5, additional special ontological languages have use: Schematic Language-SL and Elaboration Language-EL. From those that was pointe above, it follows that the SADT methodology is a technical area with standardized support of an international character, a substantial scientific and methodological substantiation and linguistic and linguistic support of software tools, which are form based on the use of specialized interfaces. 


\subsection{Evaluation methods}

Unfortunately, methods of information support systems are discuses in modern scientific periodicals magazine too, sometimes rarely and not in detail. Information support systems are despite on importance of the areas there implementation and application in various installations. It is very important that along with implementation of advanced solutions in hardware and software parts. There is need for popularization, scientific studies and conscious study of complex technical systems for their effective use [16], [17] and [18].

The methodology of building solutions in IDEF-diagrams allows us to consider a combination tasks through construction of links that take into account the total cost, monetary relations, compliance with the conditions providing improved quality indicators. They also make it possible to build models by methods of their detailed consideration through representations. For example, in graph schemes and algorithms similar to the diagram shown in fig. 3 . The development of such systems takes place in the direction on formation so-called genetic and evolutionary algorithms for constructing schemes. Binding to specific technological processes provides a detailed description of them up to elementary technological operations. There are combine into creating libraries for technological solutions. In the future, such libraries are used for provide a specific choice of how to create products.

Engineering has acquired new tools - multi-user computer's systems with distributed blocks of information support. What is it? How does this device "will fit" into already achieved technologies? To what extent do they change technological structure of machine-building industries that has become habitual?

Such systems have caused considerable interest of experts at emergence in the Russian market. Informational technological systems borrowed from foreign productions they were presents by number of perspective production plants. Innovation and re-engineering are implementation change production significantly and require a strong scientific rationale and additional training.

Specialists, who see in production for the future use as fully automated, warn about the complications of repair and maintenance such systems. They themselves become highly scientific technologies. As extreme case of improvement of automated systems - "deserted production", involve the manufacture of products without human intervention in traditional manual operations and are suitable for mass production, such as automated works on an orbital station.

Existing technical solutions share by information support system and automated control of technological processes. In the implemented solutions, distributed information systems known. In full or part of information about the product is collected. Autonomous control systems for technological devices in which information support systems had been appears yet.

It remains unclear the answer to the question about the possibility of copying production technologies based on use of "many agent information systems" with distributed databases. Work on providing such systems continue, the systems themselves have not yet acquired final form. Providing these works is quite difficult, requires special knowledge, skills on hard and software support. Progress from their use is noticeable 
in reducing the time of design, technological preparation of production, supply of materials and semi-finished products.

\subsection{Mathematical model}

Information support systems has already been testing and taken place over the past twenty years. They currently taking place at various small and medium-sized businesses, as well as in industrial and scientific enterprises and companies. It is not to mention for examples of information sites on the Internet. They also had been appears and included in the expansion of educational programs of technical undergraduate and graduate courses for subjects on University researches. On the criteria of quality assessment [10].

Effectiveness of science management at the enterprise: Let be yij $[\mathrm{i}=1(1) \mathrm{m}$; $\mathrm{j}=1(1) n]$ - quality index of the $\mathrm{i}$-th property of the $\mathrm{j}$-th object; Then suitability (or eligibility) criterion are defined as $\mathrm{m}$

$$
\mathrm{G}: \bigcap_{n \square 1}\left(\mathcal{Y}_{i j} \in\left\{y_{i j}\right\}\right),[j=1(1) n]
$$

$\left\{\mathcal{Y}_{i j}\right\}^{\nexists}$ - set values of an indicator as admissible $y i j \mathrm{e}$

Criterion of optimality:

$\mathrm{o}: \bigcap\left(\mathcal{y}_{i j} \in\left\{\mathcal{y}_{i j}{ }^{\prime}\right\}\right) \bigcap \bigcap\left(y_{k j} \leq y_{k j}^{o p t}\right),\left[j=1(1) n ; m_{o}=1(1) m\right]$

yoptkj - optimal value of the indicator with $\mathrm{k}$-th property from the $\mathrm{j}$-th object; mo - volume of the set $\{\mathrm{k}\}$ mo numbers of optimized properties.

Criterion of superiority:

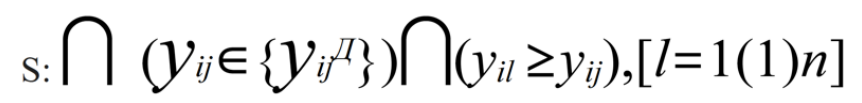

It is clear that criteria of optimality and criteria of superiority are a particular case of suitability criterion, since

$$
\begin{aligned}
& \left\{\mathcal{Y}_{k j д}\right\} \subset\left\{\mathcal{Y}_{\text {opt kj }}\right\}, 1=<k=<m \text {; and }\left\{\mathcal{Y}_{\text {ilд }\}} \bigcap\left(\mathcal{Y}_{\text {optij }}, \mathrm{G}\right)\right. \text {. } \\
& \text { In this way } \mathrm{S} \subset \mathrm{O} \subset \mathrm{G}
\end{aligned}
$$

\subsection{Gender-specific aspects}

The acceptability of innovations provides harmonization of humanitarian development of human civilization in the ideas of peacefulness, cooperation, mutual assistance 
and mutual respect, to deleting of differences in intellectual and physical types of work, without differences in sexual or national identities with comfortable conditions creating convenient conditions for vigorous activity of different age groups. Their application should not contribute to conditions for development of chronic occupational people diseases, should not lead to types of the productions directed to causing public harm. Informational and communication technologies reduce conventionalism of physical work at the same time increasing its saturation and responsibility. Basic in the nature of formation of such decisions the principles of remuneration for the spent efforts directed to obtaining concrete results act. The automated systems make essential amendments to forms of such decisions, specifying distributions on labor and active deposits of participants, busy times of workers taking into account the arising difficulties and scientific capacity of the arising types of works. It became traditionally reaches by measures for the scientific and methodical organization of works, rules of labor protection, by mean of techniques scientific management.

Scope of modern computer technologies has international character of introduction and contains communication opportunities, provides cooperation between participants of projects and countries in which they are carry out today. Many from modern amendments were not possible and are not achievable through application inside technical solutions of former generation. Potential of their development is defined by technical literacy and well organizing of scientific works in new conditions.

\section{$5 \quad$ Findings and Conclusion}

The potential of information support systems is not fully realize now and it is obvious that there are not yet realized program for their development. For example, parallelization of information flows in works helps to manage technological processes and increase the degree of communication in the division of types of work in areas and types, including geographically separated. Technologies of information support systems, together with automated technological complexes are aim for improving the quality of products performed in real-time in the production of wearing the flow character of production. It is a complex, and at the same time, effective tool that helps employees to perform production tasks in the modes of intensive loading of production. Information systems including automated control or scientific modeling of samples, processes, phenomena.

The national character of engineering education implies taking into account the innovations introduced by technologies of information systems in educational programs as a study of manufacturing technologies added devices and machines. New opportunities to create integrative forms a unifying scientific school with real production, which gives rise to the different national styles of production.

Ways of improving complex technical systems mean an explanation of the following topics: On modern technological principles.

1. On the causes that determine the quality.

2. On the criteria of quality assessment.

3. What is included in a systemic approach (in author's interpretation by Hitch)? 
4. Goals and objectives of development.

5. Analysis of alternatives.

6. Accounting (total cost analysis).

7. Mathematical model.

8. Evaluation criteria's.

The potential of information systems support is not realize fully and has obviously yet new opportunities in development today. For example, parallel information flows in works help both to operate processes and to raise extent of communication at rational division of types of works including territorially divided. Technologies of information systems support, together with the automated technological complexes is directs to improvement of indicators of products quality. They are carry out in the modes of real time in productions and same times having educational character. It is difficult, and at the same time effective tool helping workers to execute production targets in the modes of intensive loading of productions.

The national nature of engineering education means accounting to innovations introduced by technologies from other countries in educational programs when studying manufacturing techniques of devices and machines. New opportunities create integrative processes the uniting schools of sciences with real productions that generates creation of distinctions of national production styles.

As it follows from material of the article that author tried to acquaint reader with method of solutions for some technical tasks. There are in three obligatory stages characteristic of application of information and communication systems:

1. Verbal discussion of task between members of active group (the people participating in findings of the decision). About conditions in which there is a studied object its changes, etc.;

2. Formalization of mathematical problem definition (of the entry conditions studied a range of definition and sets of decisions, a design of criterion functions, etc.);

3. Applied computing hard- and software system and interpretation of the received results.

Such receptions can consider when training at the level of programs of training of bachelors and master's technic and technology.

In this article, the author shared examples and arguments that can be, in his opinion, not obvious, contain difficulties for understanding without preliminary training in the fields of engineering, science, student's environment the people then begin to apply information and communication systems without familiarity and training in rules of works with them. On the example of task solution with help information support system on practical production works (preparation of the order in furniture production), it is clear that they have both standard and original character. It is shown that for their realization the new receptions and methods (creation of IDEF charts in SADT methodology) demanding accounting of special techniques, program and hardware are used. Such difficulties can dismissed by cooperation with scientific groups taking into account preparation of methods and solutions of standard questions, inclusion of useful results in programs of teaching training courses at the higher school. The author hopes 
that similar works will assist the international cooperation and mutual understanding for creative development of human society in this direction.

\section{Acknowledgement}

The author would like to thank Leonid L. Horoshko, Anton O. Butko, Grigory E. Semyonov of colleagues on the Moscow Institute of Aircraft for useful comments and discussions.

\section{$7 \quad$ References}

[1] The Bologna Declaration of 19 June 1999. Joint declaration of the European Ministers of Education(http://www.magnacharta.org/resources/files/BOLOGNA DECLARATION.pdf) [Accessed: Dec.15.2019].

[2] Pavlov V. V. Structural control in CALS-technologies. Institute for design-technological Informatics of the RAS. - M.: Science, $2006-307$ p.

[3] D. Levin, V. Malukh, D. Ushakov and others. Encyclopedia of PLM/ Novosibirck,2008$445 \mathrm{p}$.

[4] Quality System. Quality assurance model in design, development, production, installation and maintenance. GOST R ISO 9001-96 M.: Gosstandart of Russia.

[5] The Concept of the Federal target program of development of education for 2006-2010 (app. Order of the government of the Russian Federation of September 3, 2005. No. 1340-p).

[6] Gordeev, Yusupov. Efficiency of complex technical systems. -M. Nauka, 1981.260 P.

[7] K. S. Kasaev, etc. New high technology: an encyclopedia. T10. / Edited by K. S. Kasaev. M.: SCITECH 1999 - 264 pages

[8] K. S. Kasaev, etc. New high technology: an encyclopedia. T14. / Edited by K. S. Kasaev. M.: SCITECH 1999 - p. 316

[9] Analysis of data and processes: studies. Manual / Barseghyan A. A. et al. - 2nd edition revised and additional -SPb: BHV-Petersburg, 2009 -512 p.: Il+C-ROM - (educational literature for universities).

[10] Prudnikov V. A., Sukhov G. M. Technique of technological process of designing of mechanical engineering products at the factory. // The second Scientific and practical conference of young scientists and specialists "Research and promising developments in the aviation industry". / Articles and materials of the conference, Moscow, Sukhoi design Bureau 2004. - p. 429-433.

[11] Sukhov G. M., Sukhov S. G. Automatic control systems and systems theory. Moscow: MGTU named by K. E. Tsiolkovsky, 1994.-54 p.

[12] Dr. Richard J. Mayer, Dr. Christopher P. Menzel, Michael K. Painter, Dr. Paula S. De Witte, Thomas Blind, Benjamin Perakath/ Information integration for concurrent engineering (IICE) IDEF3 process description capture method report/ Approved for public release; distribution is unlimited /1995.-p.236.

[13] The Use CAD/CAE Systems to Create E-Learning Courses on Technical Subjects at University/Leonid L Khoroshko, Peter A Ukhov, Alexey L Khoroshko [Paper. Internet resource]: International journal of Engineering Pedagogy/ Vol. 8 No2 (2018) pp. 64-71 [Online]. Available: https://doi.org/10.3991/ijep.v8i2.8134 
[14] Development of Integrated Curricula for the Master of Engineering Programs using the CDIO Framework Harold Jan Redonda Terano / [Paper]: International journal of Engineering Pedagogy/ Vol. 9 No 3 (2019) pp. 44-55 [Online]. Available: https://doi.org/10.3991/ ijep.v9i3.10112

[15] Technology, Socioeconomics and Education. Rafael Barrio / [Position Papers.]: International Journal of Advanced Corporate Learning (iJAC) / Vol 12, No 1 (2019)/pp. 67-74. [Online]. Available: https://doi.org/10.3991/ijac.v12i1.9264

[16] SADT Methodology and IDEF standards. [Online]. Available: https://lektsii.org/1212531.html [Accessed: Nov. 12, 2009].

[17] O. Andronova, I. Fighters. CALS in Russian means IPI. [Online]. Available: http://www. CALS $\backslash$ CALS in Russian means first.htm [Accessed: Jan.16.05].

[18] Modern science-intensive technologies. - 2006. - № 7 - P. 73-73 : [Online]. Available: URL:www.rae.ru/snt/?section=content\&op=show_article\&article_id=2044[Accessed: Nov.15.2018].

\section{Author}

Vitaliy A. Prudnikov is an Associate Professor, $\mathrm{PhD}$ at Aviation State University (National Research University), Moscow, Russia. Author of the published papers and books for high education. Email: Prudnikovs64@mail.ru.

Article submitted 2019-12-04. Resubmitted 2020-02-18. Final acceptance 2020-02-18. Final version published as submitted by the authors. 